\title{
Linear Array of Center Line Longitudinal Slots Excited by Double Ridge Waveguides
}

\author{
Mahdi MORADIAN ${ }^{1}$, Seyed Sajad HASHEMI ${ }^{2}$ \\ ${ }^{1}$ Young Researchers and Elite Club, Arak Branch, Islamic Azad University, Arak, Iran \\ ${ }^{2}$ Najafabad Branch, Islamic Azad University, Najafabad, Iran \\ moradianpour@gmail.com,sajadhashemi4@gmail.com
}

Submitted January 13, 2018 / Accepted May 22, 2018

\begin{abstract}
Slot antennas fed by the wiggly ridge waveguides are difficult to construct using a typical milling machine. Therefore, a special type of the double ridge waveguides is introduced here to feed the center line longitudinal slot antennas. Furthermore, in the proposed slot antennas, all the slots are placed along the waveguide center line. So, employing the proposed slot antennas leads to the elimination of the butterfly lobes that are attributed to the alternating offsets of the successive slots with respect to the centerline. In the proposed slot antennas, the ridges are placed on the lower broad walls of the waveguides while the slots are cut into the upper broad walls of the waveguides. The height of the ridges is changed gradually at the slot positions in several steps, i.e., the height of one of the ridges is increased upward while the height of the other ridges is decreased downward. It is shown that increasing the step heights leads to stronger radiation of the electromagnetic energy by the slots. To verify the effectiveness of the proposed slot antenna, a linear array antenna consisting of five slots with side-lobe level of $-20 \mathrm{~dB}$ is designed and constructed. The simulation and the measurement results show that the designing goals are achieved which verifies the effectiveness of the proposed slot antennas.
\end{abstract}

\section{Keywords}

Slotted array antennas, double ridge waveguides, second-order beams, longitudinal slots, linear arrays

\section{Introduction}

The slotted array antennas consisting of the longitudinal slots that are cut into the broad wall of the rectangular waveguides have been employed extensively due to their unique features such as linear polarization, high power handling capability and good mechanical strength. If a longitudinal slot is cut into the upper broad wall of a rectangular waveguide and along the center line of the waveguide, it does not interrupt the surface current density (associated with the dominant mode). So, no electric field develops in the slot aperture and no radiation to the outer space occurs [1]. So, for employing such kind of slots in an array, all the slots need to have offsets from the center line. Furthermore, for slots cut into the broad wall of a common waveguide, all the adjacent slots need to be cut in opposite sides of the center line in order to have an array of equiphase excitations. Unfortunately, this alternating offsets of the successive slots lead to some unwanted lobes outside of the principal planes [2], [3].

Several approaches have been introduced in the literature to solve this shortcoming [4-20]. They can be divided into two categories. In the first category, they try to introduce some methods to excite the longitudinal slots which are placed along the center line of the rectangular waveguides [4-16]. For example, it has been shown that by introducing an iris beside a center line longitudinal slot, the surface current pattern is shifted and the excitation of the slot is accomplished [4-7]. Similarly, it has been shown that conductive vertical strips can be employed to excite the longitudinal slots placed along the center line of the rectangular waveguides [8]. The performed numerical analysis has shown that the radiated electromagnetic energy by the slots can be controlled effectively by changing the position of the strips.

Another attempt has introduced tuning screws beside the center line longitudinal slots to excite them [9]. It has been shown that the amplitude of the electric field along the slots is symmetrical. So, it is possible to model such slots as equivalent shunt admittance across a two-wire transmission line. It has also been demonstrated that the depth of the screws can be used to control the radiated power by the slots. Employing conducting posts beside the longitudinal slots has been proposed to perturb the current density near the slots and excite them [10]. The successive posts are needed to locate in staggered fashion in order to excite the slots with the same phases. The radiated energy can be controlled by changing the position of the posts.

Other approaches try to perturb the sidewalls of the waveguides in different forms such that the excitation of the longitudinal slots is accomplished [11-13]. It has been shown that by controlling the perturbation of the waveguide widths, the power radiated by the slots can be con- 
trolled. In another effort, the waveguide narrow walls have been replaced by the artificial magnetic conductors [14]. The effectiveness of the proposed method has been verified by constructing a sample prototype. Employing the asymmetric ridge waveguides or wiggly ridge waveguides have also been introduced to excite the longitudinal slots aligned along the center line of the waveguides [15], [16].

In the second category and similar to the conventional array of longitudinal slots, all the slots are aligned in a staggered fashion. However, the butterfly lobes are eliminated by employing some blocks like baffles or cavities outside of the feeding waveguides [17-20]. The effective suppression of the butterfly lobes has been reported by employing the cavity or baffles outside of the feeding waveguides.

Here, the longitudinal slot antennas are fed by employing double ridge waveguides. In order to better clarify the effectiveness of the proposed slot antennas, the characteristics of the proposed slot antenna arrays are compared to the characteristics of the other proposed antennas in the literature. For this comparison, some of the results at the end of the paper are used. So, several aspects of the proposed antenna array are considered and compared to the literature which are shown in Tab. 1.

The first feature of the proposed antenna is how strongly it can radiate the electromagnetic energy. This feature can be easily studied from the normalized resonant conductance of the proposed antennas (see Fig. 6). If the maximum of the normalized resonant conductance is greater than 0.5 , one can make a conclusion that such a slot which is excited at one end at infinity, radiates more than $32 \%$ of the energy of the propagating electromagnetic wave. The radiation rating of the proposed antenna can be easily improved by increasing the height of the ridges. But, this solution sacrifices the power handling of the antenna which is another important factor of the proposed antenna. The second column of Tab. 1 compares the radiation rating of the proposed antennas to the literature. Because the maximum of the equivalent normalized shunt conductance of the proposed slot antennas is less than 0.5 (see Fig. 6), one can conclude that the radiation rating of the proposed antenna can be considered as moderate.

Another feature of the proposed antenna is its power handling. The power handling capabilities of various transmission lines have been discussed in several books [21-24]. The peak power handling of a transmission line is restricted by its maximum breakdown voltage. Among all the transmission lines, the rectangular waveguides have the highest power handling. For example, WR284 can handle pulse power higher than $2200 \mathrm{~kW}$ [24]. According to the performed discussions in [21-24], the authors concluded that at S-band, if a transmission line can handle a pulse power greater than $1000 \mathrm{~kW}$, its power handling is high. Any transmission line that can handle a pulse power less than $1000 \mathrm{~kW}$ and greater than $100 \mathrm{~kW}$ can be considered as a transmission line with moderate power handling. Finally, if the maximum power handling of a transmission line is smaller than $100 \mathrm{~kW}$, then the transmission line has low power handling. According to the simulation results of the proposed slot antenna, if one watt input power is fed to the waveguide, the maximum electric field intensity in the waveguide is equal to $53 \mathrm{~V} / \mathrm{m}$. So, considering the breakdown voltage for the air inside the waveguide indicates that the maximum tolerable pulse power of the proposed slot antennas is approximately $300 \mathrm{~kW}$. It means that the power handling of the proposed slot antennas is evaluated to be moderate as listed in the third column of Tab. 1 .

Antenna occupied area is another important factor. If an antenna is bulky, its employment in some applications would be impossible. So, this factor has been evaluated for the proposed slot antennas. This factor can be evaluated by estimating the area occupied by the cross section of the antennas which was classified into three groups as listed in Tab. 1. Because the occupied area by the cross section of the proposed slot antennas (see Sec. 3) is $0.07 \lambda_{0}^{2}$, one can conclude its occupied area is moderate.

The construction process of the proposed antenna is also an important factor. It is clear that difficult construction process of an antenna increases the total cost of that antenna. In order to reach a better conclusion about the construction difficulty of the proposed slot antennas, the construction process of the proposed slot antennas is compared to the construction process of the slot antennas fed by the wiggly ridge waveguide [16]. In [16], each wiggly ridge has two slant sections under the slots of the array. So, the construction of each wiggly ridge has to be done in two steps, if one wants to use a typical milling machine. First the straight sections are usually milled. Then, the slant sections are milled. Please note that each wiggly ridge has its own slope. This shortcoming encouraged the authors to look for an alternative method for exciting the center line longitudinal slot antennas. Hence, another method is introduced here to feed the center line longitudinal slot antennas. Because in the proposed method, the ridges do not have any slant sections, their construction can be done in only one step. So, from a mechanical point of view, the construction of the proposed slot antennas is easier than the slot antennas proposed in [16]. According to the discussion, the construction process of the proposed antenna has been evaluated to be moderate.

Most of the introduced antennas in the literature are not tunable. It means that after construction of the antennas, it is not possible to change the antenna radiation features anymore. The proposed antennas are also non tunable. The sixth column of Tab. 1 compares the tunablity of the antennas. As the table shows, only the antennas proposed in [10] are tunable.

The bandwidth and the side-lobe level of the proposed antennas are also compared to the antennas introduced in the literature (see Sec. 6). The seventh and eighth columns of Tab. 1 show these comparisons. According to the table, the antenna bandwidth is $4 \%$ which is equal to or greater than the bandwidth of the most of the other proposed antennas. 


\begin{tabular}{|c|c|c|c|c|c|c|c|}
\hline Refs. & $\begin{array}{c}\text { Radiation rating } \\
\text { of an element: } \\
\mathrm{G} / \mathrm{G}_{0}>0.5 \text { strong } \\
G / G_{0}<0.5 \\
\text { moderate } \\
\end{array}$ & $\begin{array}{c}\text { Power handling: } \\
1000 \mathrm{~kW}<P_{\max } \text { high } \\
100 \mathrm{~kW}<P_{\max }<1000 \mathrm{~kW} \\
\text { moderate } \\
100 \mathrm{~kW}>P_{\max } \text { low }\end{array}$ & $\begin{array}{c}\text { Antenna occupied area } \\
\text { (AOA): } \\
A O A>0.3 \lambda_{0}^{2} \text { large } \\
0.05 \lambda_{0}^{2}<A O A \approx 0.3 \lambda_{0}^{2} \text { moderate } \\
A O A<0.05 \lambda_{0}^{2} \text { small } \\
\end{array}$ & $\begin{array}{c}\text { Manufacturing } \\
\text { process }\end{array}$ & Tunability & Bandwidth & $\begin{array}{c}\text { Side-lobe } \\
\text { level }\end{array}$ \\
\hline Ref. [10] & strong & high & moderate & easy & possible & $2 \%$ & -30 \\
\hline Ref. [12] & strong & high & moderate & very difficult & not possible & $4 \%$ & -17 \\
\hline Ref. [13] & strong & low & small & easy & not possible & $4 \%$ & -24 \\
\hline Ref. [14] & strong & moderate & moderate & moderate & not possible & $1 \%$ & -21 \\
\hline Ref. [15] & moderate & high & moderate & difficult & not possible & $4 \%$ & -26 \\
\hline Ref. [16] & moderate & moderate & moderate & difficult & not possible & $7 \%$ & -20 \\
\hline Ref. [20] & strong & high & large & difficult & not possible & $5 \%$ & -13 \\
\hline This work & moderate & moderate & moderate & moderate & not possible & $4 \%$ & -19 \\
\hline
\end{tabular}

Tab. 1. Comparison between the performance of the proposed antennas and the antennas proposed in the literature.

\section{The Proposed Antenna Element}

The proposed antenna including its various parameters is shown in Fig. 1. According to the figure, the waveguide has two similar ridges which are symmetrical with respect to the waveguide center line. The figure also shows that a longitudinal slot is cut into the upper broad wall of the waveguide and placed exactly along the waveguide center line. At the slot position, the height of one of the ridges is increased gradually in several equal steps, while in the opposite fashion, the height of the other ridge is decreased gradually. It is clear that selecting equal heights for the ridges while the slot is cut along the center line of the waveguide, leads to no radiation.

According to the figure, the feeding ridge waveguide has several physical parameters (i.e. waveguide width and its height, ridge widths and their heights and offset of the ridges from the waveguide center line). These physical parameters dictate the transverse electric field pattern and the propagation constant of the dominant mode at the design frequency [25]. The relationship between physical parameters of the ridge waveguides and the propagation characteristics have been discussed in depth in [25] and it is not worthwhile to discuss it here anymore.

In the following section, three different physical dimensions are selected for the feeding waveguide and the effects of these dimensions on the performance of the proposed slot antennas are discussed.

\section{Effect of the Feed Dimensions on the Performance of the Proposed Slot Antennas}

As it has already been noted, the physical dimensions of the feeding waveguide have effect on the performance of the proposed antennas. It is not possible to investigate the effect of all the physical parameters of the feeding waveguide on the performance of the proposed antennas. So, three different physical dimensions have been selected for the feeding waveguide that leads to the same propagation constants of the dominant mode. The considered

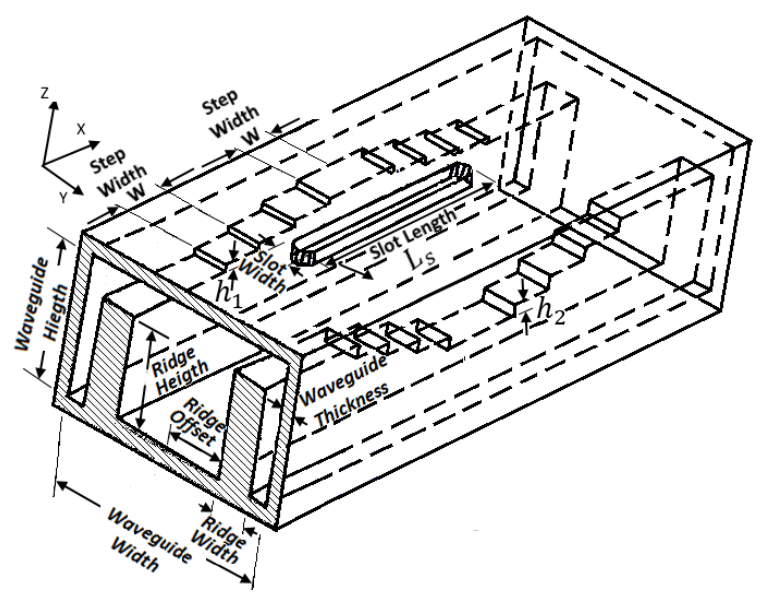

Fig. 1. The proposed slot antenna and its various parameters.

physical dimensions are listed in the first column of Tab. 2 . According to the table, only the waveguide width, the ridge height and the ridge offset are taken as variables and the other physical dimensions are fixed (i.e. waveguide height and ridge widths). Then, the simulation of the proposed antenna has been carried out using ANSYS high frequency structure simulator.

Three different values have been selected for step height $h_{1}$ that are listed in the second column of Tab. 2. As it will be explained later, the step height $h_{2}$ is a function of step height $h_{1}$. For each step height $h_{1}$, the proper value for the step height $h_{2}$ is listed in the third column of Tab. 2 . Finally, for each values of step heights $h_{1}$ and $h_{2}$, the obtained values for the equivalent normalized shunt conductances and their corresponding resonant lengths are shown in the fourth and fifth columns (the reason for considering the proposed slot antenna as an equivalent shunt admittance will emerge later). The equivalent normalized shunt admittances are derived from the reflection coefficient by de-embedding the scattering parameters and then by employing the following equation

$$
\frac{Y}{G_{0}}=\frac{-2 S_{11}}{1+S_{11}}
$$

where $Y / G_{0}$ is the equivalent normalized shunt admittance and $S_{11}$ is the input reflection coefficient. The results indicate 


\begin{tabular}{|c|c|c|c|c|}
\hline & $h_{1}(\mathrm{~mm})$ & $h_{2}(\mathrm{~mm})$ & $G / G_{0}$ & $l_{\mathrm{r}}(\mathrm{mm})$ \\
\hline \multirow{3}{*}{$\begin{array}{l}\text { Ridge offset }=3 \mathrm{~mm} \\
\text { Ridge height }=16 \mathrm{~mm} \\
\text { Waveguide width }=31 \mathrm{~mm}\end{array}$} & 0.2 & 0.29 & 0.1 & 51.5 \\
\hline & 0.3 & 0.71 & 0.29 & $\begin{array}{l}51.8 \\
\end{array}$ \\
\hline & 0.4 & 2.5 & 0.58 & 52 \\
\hline \multirow{3}{*}{$\begin{array}{l}\text { Ridge offset }=3 \mathrm{~mm} \\
\text { Ridge height }=15 \mathrm{~mm} \\
\text { Waveguide width }=33.8 \mathrm{~mm}\end{array}$} & 0.2 & 0.27 & 0.05 & 51 \\
\hline & 0.3 & 0.55 & 0.13 & 51.4 \\
\hline & 0.4 & 1.05 & 0.26 & $\begin{array}{l}51.5 \\
\end{array}$ \\
\hline \multirow{3}{*}{$\begin{array}{l}\text { Ridge offset }=6 \mathrm{~mm} \\
\text { Ridge height }=16 \mathrm{~mm} \\
\text { Waveguide width }=34.8 \mathrm{~mm}\end{array}$} & 0.2 & 0.34 & 0.13 & $\begin{array}{l}50.5 \\
\end{array}$ \\
\hline & 0.3 & 0.8 & 0.35 & 51.0 \\
\hline & 0.4 & 3.0 & 0.65 & 51.25 \\
\hline
\end{tabular}

Tab. 2. The characteristics of the proposed slot antenna for three different waveguide parameters.

that if the ridge heights are decreased then the equivalent shunt conductances are also decreased. The equivalent shunt conductances are increased as the ridge offsets are increased. For all cases, both the resonant lengths and the equivalent shunt admittances are increased as the step height $h_{1}$ is increased.

Although there are many possibilities to select the physical dimensions of the feeding waveguides, but due to the availability of the aluminum rectangular tubes and slabs in the standard sizes, the following dimensions were selected for the feeding waveguide. This selection leads to saving time and effort to construct a sample prototype of the proposed antenna.

The inner waveguide width and height were 31 and $21 \mathrm{~mm}$, respectively. The slot widths were selected to be equal to $3 \mathrm{~mm}$. The step widths and ridge offsets were equal to 6.25 and $3 \mathrm{~mm}$, respectively. The ridge widths and waveguide thickness were also selected to be equal to 5 and $2 \mathrm{~mm}$, respectively. The aforementioned cross-sectional dimensions were selected such that only a dominant mode can propagate along the waveguide at $3 \mathrm{GHz}$.

\section{Electric Field Distribution along the Slot}

Electric field distribution along the slot is one of the most important factors in the study of slot antennas. As it has been discussed in [26], in order to justify that the proposed slot antennas can be represented as an equivalent shunt admittance on an equivalent transmission line, it needs to be shown first that the electric field distribution along the slot is symmetrical. Otherwise, the forward and backward amplitudes of the dominant mode scattering off the proposed slot antennas are not equal and in phase.

Furthermore, it has been shown that for the slot antennas fed by the rectangular waveguides, when the offset of the slots is too large or too small, the slot antennas cannot be represented as an equivalent normalized shunt admittance on a transmission line [26], [27]. Although, the offset of the slots is zero in the currently proposed slot antennas, but step height is considered here as a counterpart with the slot offsets in the rectangular waveguide fed slot antennas. So, the validity of representing the proposed slot antennas as equivalent shunt admittance on a transmis- sion line is investigated when the step height is selected to be very small or very large. Please note that when the step height is too large, the ridge approximately touches the lower broad wall of the waveguide (increasing the step height no longer will be possible). In addition, the step height is too small when the equivalent normalized resonant conductance of the antenna is approximately equal to zero.

For study the electric field distribution in the slots, first, the simulation of the antenna was done for step height $h_{1}$ equal to $0.1 \mathrm{~mm}$ and for three different values of slot lengths (i.e. the resonant length, $5 \%$ below and above the resonant length). This selection is related to the fact that in an antenna array consisting of the longitudinal slots, the length of all the slots in the array range from $0.95 l_{\mathrm{r}}$ to $1.095 l_{\mathrm{r}}$. In addition, because the slot width is much smaller than the slot length, it is expected that the transverse component of the electric field is much larger than longitudinal component. So, only the transverse components of the electric fields along the center line of the slot are considered here. Figure 2 shows the amplitudes and the phases of the transverse electric field distributions versus the normalized slot length for the proposed slot antennas. Similarly, Figure 3 shows the amplitudes and phases of the transverse electric field distributions versus the normalized slot length while the step height was selected to be equal to $0.4 \mathrm{~mm}$ and for three different slot lengths. For comparison reasons, the half-sinusoid is also added to the figures. Because the resonant length is approximately equal to onehalf of the free space wavelength, it was expected that the transverse electric field can be represented by half-sinusoid. However, half-cosinusoid is better choice for all the cases (for example when the proposed slot antenna covers with dielectric slab) [26].

The results indicate that for both step heights (corresponding to the smallest and largest values of the normalized resonant conductances), the transverse electric fields are in accordance with the half-sinusoid. In addition, the phase of the transverse electric fields changes slightly

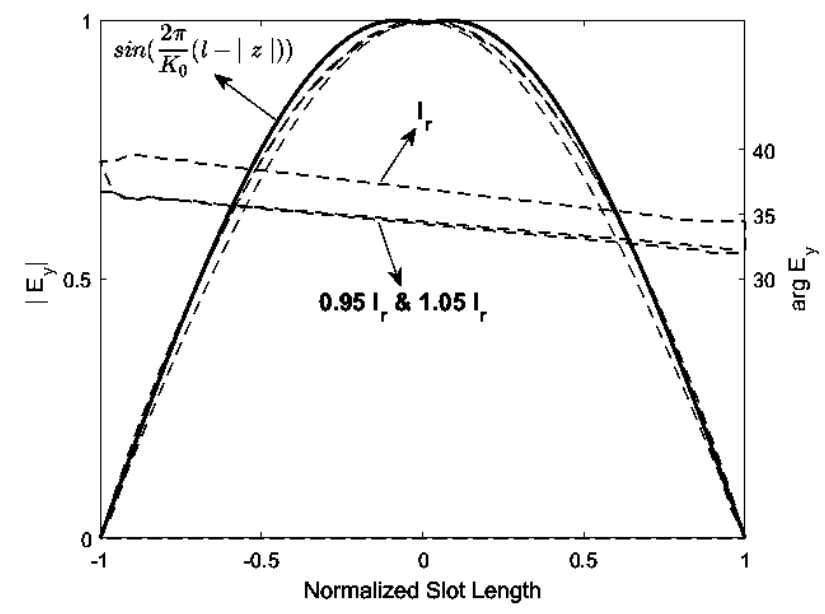

Fig. 2. Electric field distribution versus normalized slot length for step height equal to $0.1 \mathrm{~mm}$. 


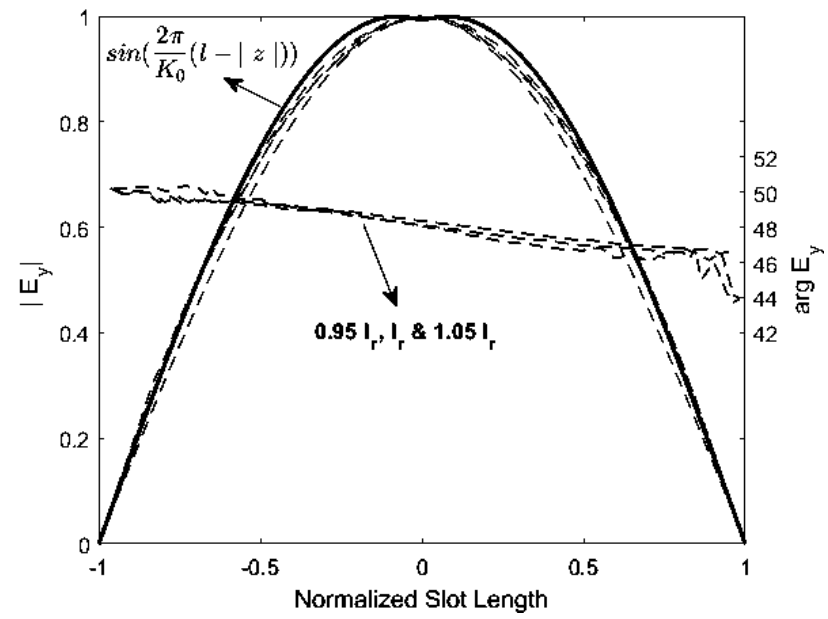

Fig. 3. Electric field distribution versus normalized slot length for step height equal to $0.4 \mathrm{~mm}$.

against the normalized length and they can be considered roughly constant along the slot. Overall, the transverse electric field along the proposed slot antennas can be represented by half-sinusoid. Furthermore, considering the proposed slot antennas as equivalent shunt admittances on artificial transmission lines is valid.

\section{Deriving the Design Graphs for the Proposed Slot Antennas}

To derive design graphs for the proposed antennas, the previously defined model in HFSS was simulated while the slot length and step heights were swept. The slot length was swept from 47 to $55 \mathrm{~mm}$ in $0.5 \mathrm{~mm}$ steps. The step heights $h_{1}$ and $h_{2}$ are swept from 0 to $0.35 \mathrm{~mm}$ in $0.02 \mathrm{~mm}$ steps and from 0 to $1.4 \mathrm{~mm}$ in $0.06 \mathrm{~mm}$ steps, respectively. The scattering parameters of the model for various slot lengths and step heights were obtained and saved. Then, equivalent shunt admittances were derived for each slot length and ridge height.

By definition, the resonant length of a slot is a length for which the corresponding susceptance of the equivalent shunt admittance is equal to zero. For a longitudinal slot fed by the rectangular waveguide, at resonance not only the susceptance of the equivalent shunt admittances is equal to zero but also the conductance of the equivalent shunt admittance is maximum. Unfortunately, for the proposed slot antennas, negligible susceptances and maximum conductances of the equivalent shunt admittances are only achieved simultaneously, when the step height $h_{2}$ is selected appropriately with respect to step height $h_{1}$. On the other hand, in order to find the Stegen's design graphs for the proposed slot antenna, an appropriate function which represents $h_{2}$ versus $h_{1}$ needs to be first derived. Figure 4 shows the required function that represents $h_{2}$ versus $h_{1}$. As it was mentioned earlier, various parameters of the proposed slot antennas were swept in some special ranges and the scattering parameters were saved and then analyzed to find the equivalent normalized shunt admittances. In the next step, the appropriate function which represents $h_{2}$ versus $h_{1}$ was derived from the normalized equivalent shunt admittances. It is clear that if one selects other dimensions for the feeding waveguide, the introduced function in Fig. 4 is not useful anymore.

Based on the obtained equivalent shunt admittances, the resonant lengths multiplied by the wavenumber and the equivalent normalized conductance versus the step height were also calculated that are shown in Fig. 5 and Fig. 6, respectively. The equivalent normalized conductances and susceptances of the slot antenna against the normalized length and for various step heights are also shown in Fig. 7. Two proper curves were also being fitted to the provided data that can be used in a computer code to design an array of the proposed slot antennas. Figure 7 is unavoidable if one needs to employ the proposed slot antennas in a planar antenna arrays. Except the data associated with the step height equal to $0.1 \mathrm{~mm}$, there is a good agreement between the fitted curves and the other data points. Please note that the fitted curve to the equivalent normalized shunt susceptances around the resonant length is a linear function of the normalized length. The derived design graphs can be used to design arrays of the proposed slot antennas as will be described in the following section.

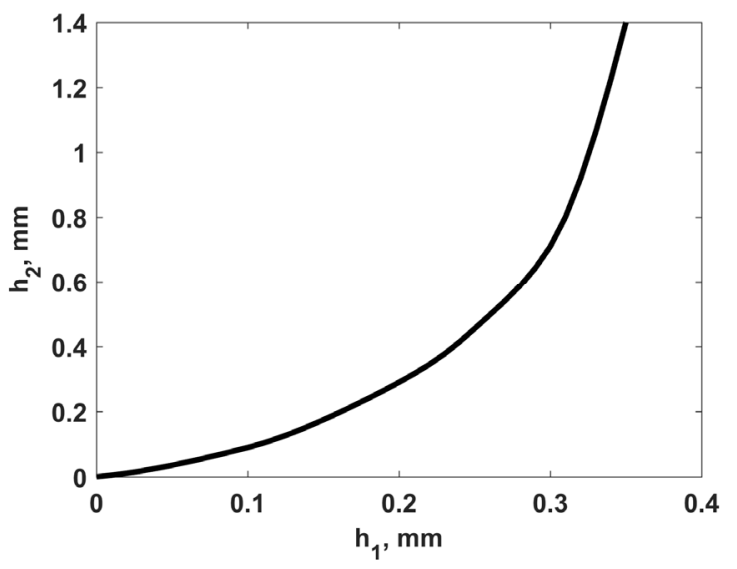

Fig. 4. The variation of $h_{2}$ against the step height, mm.

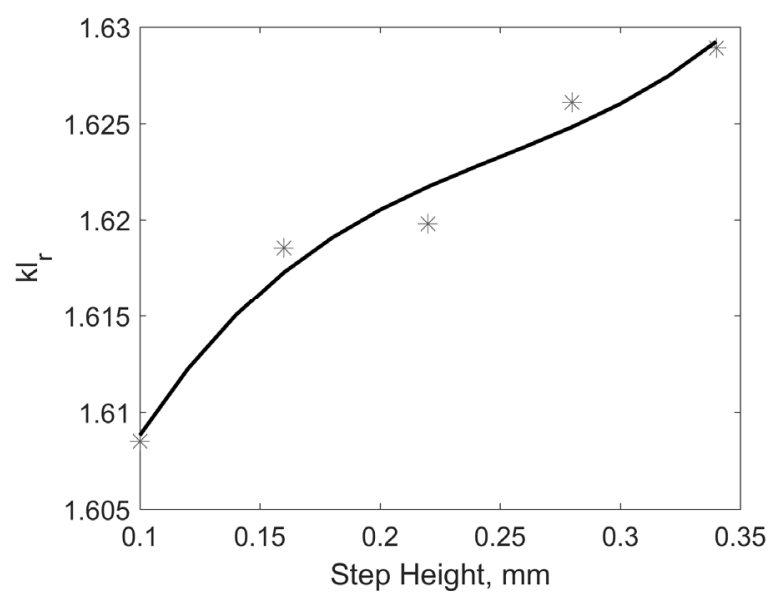

Fig. 5. The resonant length multiplied by the free space wavenumber against the step height. 


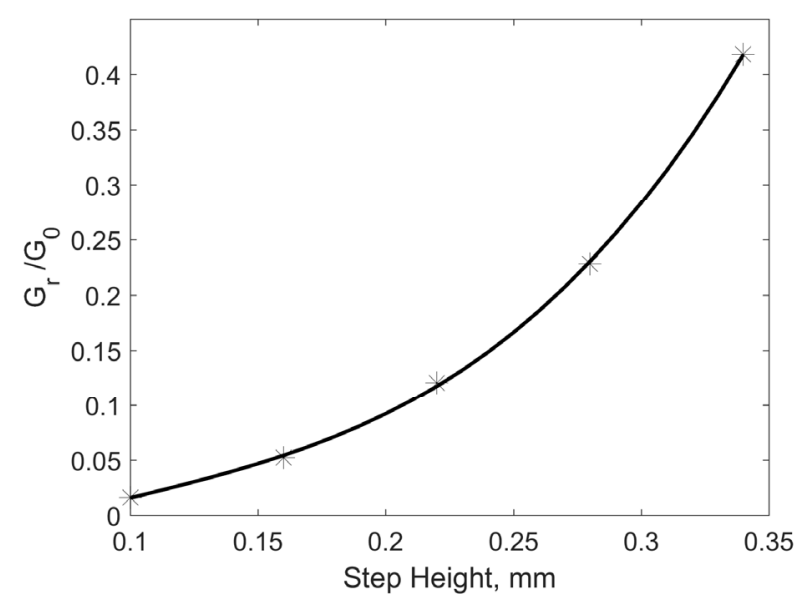

Fig. 6. The normalized resonant conductance against the step height.

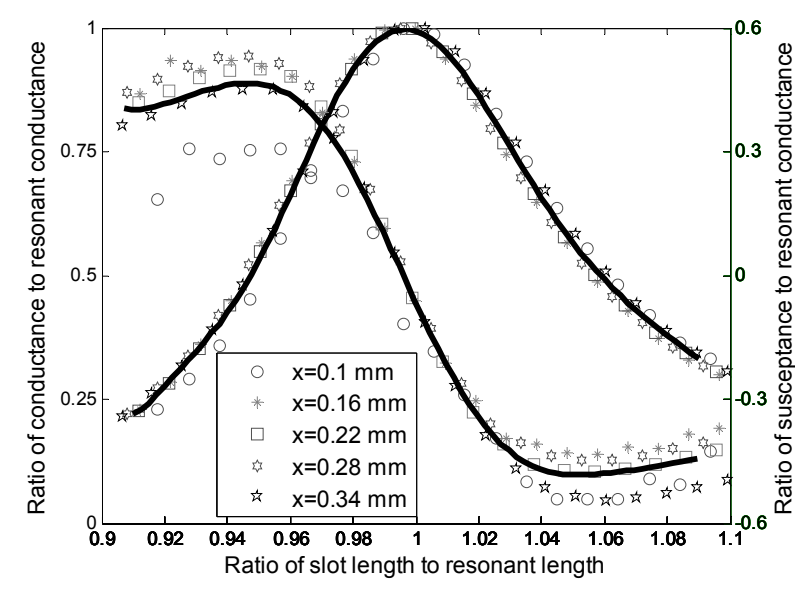

Fig. 7. The normalized conductance and susceptance versus the normalized slot length.

\section{Antenna Design and Results}

Designing of a standing wave array antenna consisting of the proposed slot antennas at $3 \mathrm{GHz}$ was performed by employing the previously derived design graphs. The antenna has 5 slots with Taylor windowing $(n=2$, SLL $=$ $20 \mathrm{~dB}$ ). The shape and the decaying behavior of the sidelobes of an antenna array can be effectively controlled if one selects the Taylor windowing for the array. The element excitations can be derived by employing some analytical formulas [1]. The design of the array has been easily done by considering the required voltage excitation for each slot and employing Fig. 5 and 6. It was also assumed that the amount of the power radiated by each slot is proportional to the square of its voltage.

The side view of the designed antenna and its dimensions are shown in Fig. 8. A simple transition from coaxial line to the double-ridged waveguide was also required that was designed and is shown in Fig. 8. The construction of the designed antenna was done by using a typical milling machine. Figure 9 shows a photograph of the fabricated structure. The reflection coefficient of the array was meas-

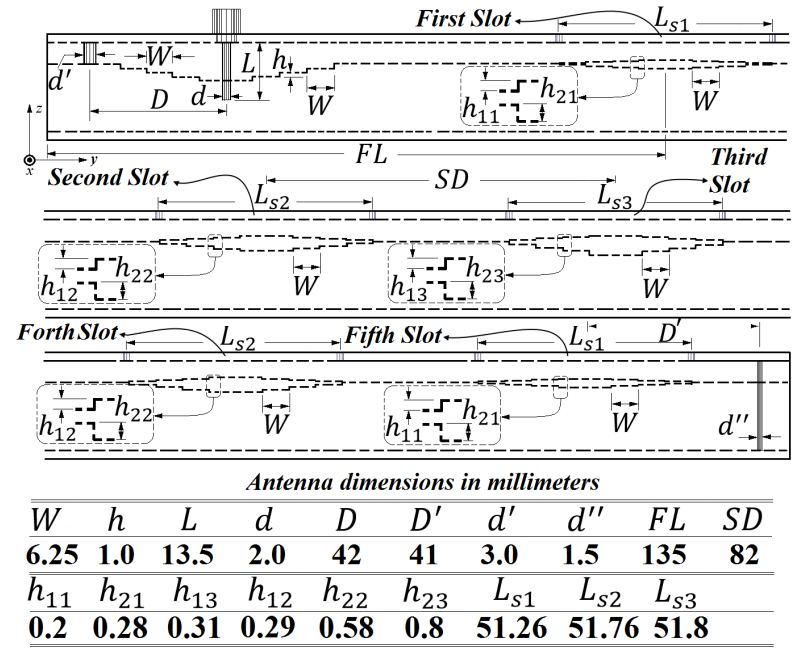

Fig. 8. A side view of the designed antenna and its various dimensions.

ured that is shown along with the simulated result in Fig. 10. Except some frequency shift, the simulated and measurement results are in good agreement.

The radiation patterns of the antenna were also measured at $3.0 \mathrm{GHz}$. Figure 11 shows the measured and the simulated co- and cross-polarized radiation patterns of the antenna in E-plane. The figure shows that the simulated side-lobe level of the designed array is in good agreement with the specified design goal (SLL $=-20 \mathrm{~dB})$. As Figure 11 shows, the measured side-lobe levels are approximately equal to $-19 \mathrm{~dB}$ which is one decibel larger than the desired side-lobe level $(-20 \mathrm{~dB})$. The simulated cross-polarized level is also smaller than the measured cross-polarized level. That is because the limited sensitivity of the power meter which was used for the measurement and did not allow the authors to detect very small signals.

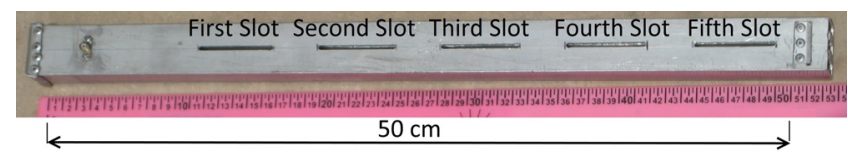

Fig. 9. A photograph of the constructed antenna.

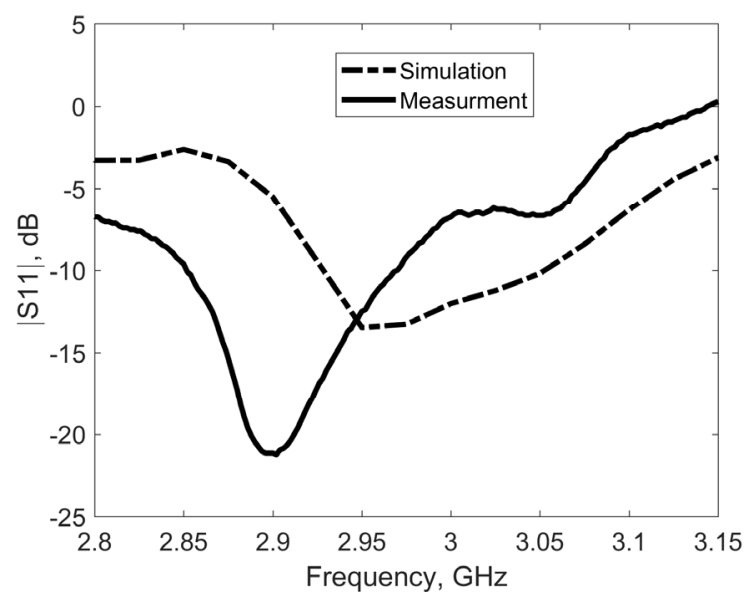

Fig. 10. The simulated and measured reflection coefficient versus frequency. 


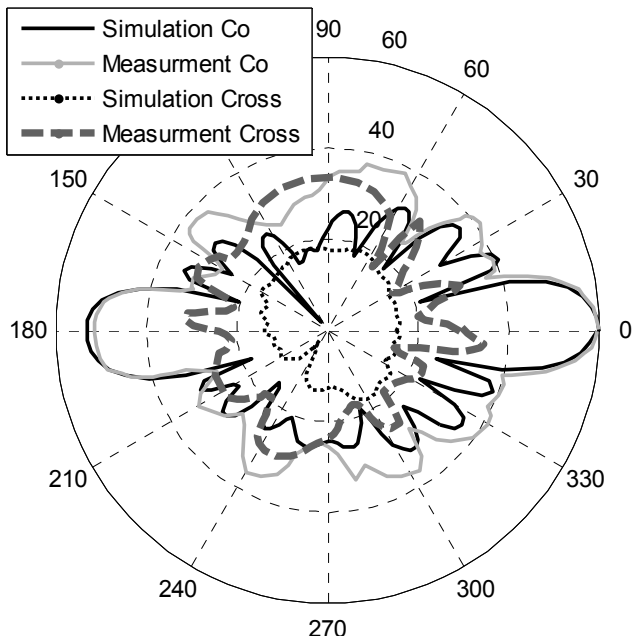

Fig. 11. Simulated and measured E-plane-normalized radiation patterns of the designed antenna.

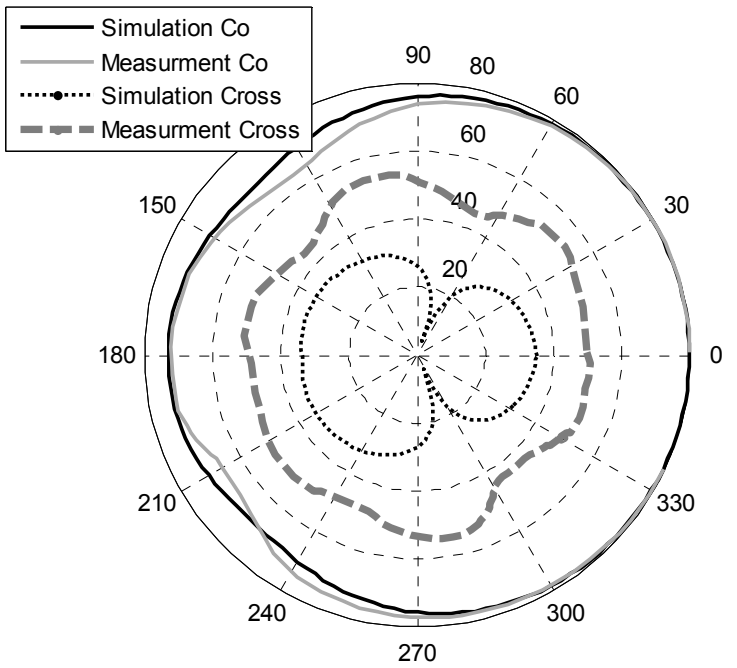

Fig. 12. Simulated and measured H-plane-normalized radiation patterns of the designed antenna.

Figure 12 shows the measured and the simulated coand cross-polarization radiation patterns of the antenna in $\mathrm{H}$-plane. According to the figure, there is a good agreement between the simulated and the measured radiation patterns. However, similar to the E-plane radiation pattern, the measured level of the cross-polarized pattern is greater than the level of the simulated cross-polarized pattern. Because the antenna has been constructed using a typical milling machine, it can be concluded that the differences between the measured and the simulated return losses and the radiation patters are due to the construction tolerances.

Overall, according to the discussion and Tab. 1, the proposed antenna can be a good candidate in some applications which require small spacing between elements (to better sampling the continuous aperture distribution which eventually leads to the smaller pattern degradation), furthermore, in the applications where the cost of the construction, the power handling and the total occupation volume are also important.

\section{Conclusion}

A new method for exciting the center line longitudinal slots was introduced. A double ridge waveguides were employed to feed the proposed slot antennas such that the required slot offset that is unavoidable in the longitudinal slot antennas fed by the rectangular waveguides was eliminated. The required design graphs were obtained for the proposed structure and an array of the proposed antenna was designed and constructed. The design method for the proposed slot antenna needs to be extended for the case of planar array of the proposed slots. Except some discrepancies in the return losses and the radiation patterns, the simulation and measurement results indicated the usefulness of the proposed slot antennas and the validation of the presented design method.

\section{References}

[1] ELLIOTT, R. S. Theory of waveguide-fed slot radiators. In Elliott, R. S. Antenna Theory and Design. Rev. ed. New Jersey (USA): John Wiley \& Sons, 2003. P. 91-99. ISBN: 978-0-471-44996-6

[2] KURTZ, L. A., YEE, J. S. Second-order beams of two dimensional slot arrays. IRE Transactions on Antennas and Propagation, 1957, vol. 5, no. 4, p. 356-362. DOI: 10.1109/TAP.1957.1144524

[3] DERNERYD, A. Butterfly lobes in slotted waveguide antennas. In 1987 Antennas and Propagation Society International Symposium. Blacksburg (VA, USA), 1987, p. 15-19. DOI: 10.1109/APS.1987.1150038

[4] CHATTERJEE, S., GHATAK, R., PODDAR, D. R. Analysis of asymmetric iris excited centered slot antenna on the broadwall of rectangular waveguide. In 2011 International Conference on Information and Electronics Engineering IPCSIT. Bangkok (Thailand), May 2011, p. 75-79.

[5] PARK, P. K., KIM, H. D. Centered Longitudinal Shunt Slot Fed by a Resonant Offset Ridge Iris. European Patent - EP 0988662 B1, Bulletin 2000/13, 29.03.2000, p. 1-9.

[6] GOEBles, F. J., FORMAN, B. J., NONEMAKER, C. H. Scanning of linear slot arrays using diode irises. IEEE Transactions on Antennas and Propagation, 1968, vol. 16, no. 1, p. 8-14. DOI: 10.1109/TAP.1968.1139106

[7] TANG, R. A. Slot with variable coupling and its application to a linear array. IEEE Transactions on Antennas and Propagation, 1960, vol. 8, no. 1, p. 97-101. DOI: 10.1109/TAP.1960.1144812

[8] DATTA, A., CHAKARABORTY, A., DAS, B. Analysis of a strip loaded resonant longitudinal slot in the broad wall of a rectangular waveguide. IEE Proceedings $H$ (Microwaves, Antennas and Propagation), 1993, vol. 140, no. 2, p. 135-140. DOI: 10.1049/iph-2.1993.0021

[9] AZAR, T. J. Analysis of slotted waveguide antenna array excited by tuning screws. PhD Thesis, Drexel University, 1998.

[10] LIM, K. S., KOO, V. C., LIM, T. S. Design, simulation and measurement of a post slot waveguide antenna. Journal of Electromagnetic Waves and Applications, 2007, vol. 21, no. 12, p. 1589-1603. DOI: $10.1163 / 156939307781870880$

[11] ANAND, A., DAS, S. A novel virtually centred broad wall longitudinal slot for antenna application. International Journal of 
RF and Microwave Computer-Aided Engineering, 2010, vol. 20, no. 3 , p. 272-278. DOI: $10.1002 /$ mmce. 20430

[12] KHAZARI, M., KHALAJ-AMIRHOSSEINI, M. To reduce side lobe level of slotted array antennas using nonuniform waveguides. International Journal of $R F$ and Microwave Computer-Aided Engineering, 2016, vol. 26, no. 1, p. 42-46. DOI: 10.1002/mmce. 20936

[13] MALLAHZADEH, A., MOHAMMAD-ALI-NEZHAD, S. A low cross-polarization slotted ridged SIW array antenna design with mutual coupling considerations. IEEE Transactions on Antennas and Propagation, 2015, vol. 63, no. 1, p. 4324-4333. DOI: 10.1109/TAP.2015.2457952

[14] ESMAELI, S. H., SEDIGHY, S. H. Side lobe level reduction of slot array antenna by artificial magnetic conductor side walls. Electronics Letters, 2016, vol. 52, no. 1, p. 1513-1514. DOI: $10.1049 / \mathrm{el} .2016 .2430$

[15] GREEN, J., SHNITKIN, H., BERTALAN, P. J. Asymmetric ridge waveguide radiating element for a scanned planar array. IEEE Transactions on Antennas and Propagation, 1990, vol. 38, no. 8, p. 1161-1165. DOI: 10.1109/8.56951

[16] MORADIAN, M., KHALAJ-AMIRHOSSEINI, M., TAYARANI, M. Application of wiggly ridge waveguide for design of linear array antennas of centred longitudinal shunt slot. International Journal of $R F$ and Microwave Computer-Aided Engineering, 2009, vol. 19 , no. 6, p. 717-726. DOI: $10.1002 /$ mmce. 20396

[17] RENGARAJAN, S. R. Mutual coupling between waveguide-fed longitudinal broad wall slots radiating between baffles. Electromagnetics, 1996, vol. 16, no. 6, p. 671-638. DOI: $10.1080 / 02726349608908507$

[18] FOROORAGHI, K., KILDAL, P. S. Reduction of second order beams in slotted waveguide array using baffles. In IEE International Conference on Antennas and Propagation. York (England), April 1991, p. 725-728. ISBN: 0-85296-508-7

[19] SUZUKI, T., HIROKAWA, J., ANDO, M. Iteration-free design of waveguide slot array with cavities. IEEE Transactions on Antennas and Propagation, 2010, vol. 58, no. 12, p. 3891-3897. DOI: $10.1109 /$ TAP.2010.2078435

[20] MONTISCI, G., MAZZARELlA, G., CASUlA, G. A. Effective analysis of a waveguide longitudinal slot with cavity. IEEE Transactions on Antennas and Propagation, 2012, vol. 60, no. 7 , p. 125-138. DOI: 10.1109/TAP.2012.2196953
[21] COLLIN, R. Foundations for Microwave Engineering. New York: IEEE Press; 2001. ISBN: 978-0-7803-6031-0

[22] POZAR, D. Microwave Engineering. Hoboken (NJ): Wiley; 2012. ISBN: 978-0-470-63155-3

[23] EDWARDS, T. Foundations for Microstrip Circuit Design. New York: Wiley-Interscience, 1981. ISBN: 978-1-118-93619-1

[24] RIZZI, P. Microwave Engineering. Estados Unidos: Prentice Hall; 1988. ISBN-10: 0135867029

[25] HELSZAJN, J. Ridge Waveguide and Passive Microwave Components. Institution of Electrical Engineers, 2000. ISBN: 9780-85296-794-2

[26] STERN, G. J., ELLIOTT, R. S. Resonant length of longitudinal slots and validity of circuit representation: Theory and experiment. IEEE Transactions on Antennas and Propagation, 1985, vol. 33, no. 11 , p. 1264-1271. DOI: 10.1109/TAP.1985.1143509

[27] MCNAMARA, D., JACOBS, J., JOUBERT, J. Form of field in small-offset longitudinal slot in broad wall of rectangular waveguide. Electronics Letters, 1992, vol. 28, no. 1, p. 16-17. DOI: 10.1049/el:19920010

\section{About the Authors ...}

Mahdi MORADIAN was born in Iran. He received the B.Sc. degree in Electrical Engineering from the Islamic Azad University, Najafabad Branch, in 2001, and the M.Sc. and Ph.D. degrees both in Electrical Engineering from the Iran University of Science and Technology, Tehran, Iran, in 2004 and 2011, respectively. Since his graduation, he has worked in several institutes and universities as lecturer and research engineer.

Seyed Sajad HASHEMI was born in Iran. He received his B.Sc. and M.Sc. from the Islamic Azad University, Najafabad Branch, Isfahan, Iran, in 2009 and 2014, respectively. After his graduation he has worked with several companies. 